Article

\title{
Irradiation Maintains Functional Components of Dry Hot Peppers (Capsicum annuum L.) under Ambient Storage
}

\author{
Qumer Iqbal ${ }^{1, *}$, Muhammad Amjad ${ }^{1}$, Muhammad Rafique Asi ${ }^{2}$, Aamir Nawaz $^{3}$, \\ Samiya Mahmood Khan ${ }^{3}$, Agustin Ariño ${ }^{4}$ and Tanveer Ahmad ${ }^{5}$ \\ 1 Institute of Horticultural Sciences, University of Agriculture, Faisalabad 38000, Pakistan; \\ amjaduaf@gmail.com \\ 2 Nuclear Institute for Agriculture and Biology (NIAB), Faisalabad 38000, Pakistan; \\ asimuhammad@yahoo.co.uk \\ 3 Faculty of Agricultural Sciences and Technology, Bahauddin Zakariya University, Multan 60000, Pakistan; \\ aamirkhan_74@hotmail.com (A.N.); drsamiyakhan@hotmail.com (S.M.K.) \\ 4 Instituto Agroalimentario de Aragón (IA2), Veterinary Faculty, Universidad de Zaragoza-CITA, \\ 50013 Zaragoza, Spain; aarino@unizar.es \\ 5 Department of Horticulture, Faculty of Agricultural Sciences, Ghazi University, \\ Dera Ghazi Khan 32200, Pakistan; horticulture.tanveer@gmail.com \\ * Correspondence: qumerhort@gmail.com; Tel.: +92-347-749-2734
}

Academic Editor: Monique Lacroix

Received: 10 June 2016; Accepted: 7 September 2016; Published: 12 September 2016

\begin{abstract}
Hot peppers used as natural flavoring and coloring agents are usually irradiated in prepacked form for decontamination. The effects of gamma radiation on the stability of functional components such as capsaicinoids and antioxidant compounds (carotenoids, ascorbic acid and total phenolics) were investigated in hot peppers (Capsicum annuum). Whole dried peppers packed in polyethylene bags were gamma irradiated at 0 (control), 2, 4, and $6 \mathrm{kGy}$ and subsequently stored at $25^{\circ} \mathrm{C}$ for 90 days. The irradiation dose did not substantially affect the initial contents of capsaicinoids, ascorbic acid and total phenolics, though the concentration of carotenoids declined by $8 \%$ from the control $(76.9 \mathrm{mg} / 100 \mathrm{~g})$ to $6 \mathrm{kGy}$ radiation dose $(70.7 \mathrm{mg} / 100 \mathrm{~g})$. Similarly, during storage for 90 days at ambient temperature the concentrations of capsaicinoids and total phenolics remained fairly stable with mean percent reductions from $3.3 \%$ to $4.2 \%$, while the levels of total carotenoids and ascorbic acid significantly $(p<0.05)$ declined by $12 \%$ and $14 \%$, respectively. Overall, neither irradiation nor subsequent ambient storage could appreciably influence the contents of functional components in hot peppers. These results revealed that gamma irradiation up to $6 \mathrm{kGy}$ can be safely used for decontamination to meet the needs for overseas markets without compromising product quality.
\end{abstract}

Keywords: gamma radiation; hot pepper; capsaicinoids; antioxidants; quality; storage

\section{Introduction}

Dry hot pepper (Capsicum annum L.) is one of the most important spices used worldwide as a natural flavoring and coloring agent owing to its unique spicy and pungent taste and color. In addition, peppers are a rich source of nutrients and diverse bioactive compounds with potential health-promoting properties, such as capsaicinoids and antioxidant compounds [1]. However, pepper is generally contaminated by molds, yeast and bacteria during the cultivation, drying, packaging, and storage processes. Therefore, to sanitize pepper, fumigation, steam heat sterilization, and irradiation are used to decontaminate undesirable microorganisms [2]. Interest in the ionizing radiation process is increasing because of persistently high food losses from infestation, contamination and spoilage, 
mounting concerns over food-borne diseases and growing international trade in food products that must meet strict import standards of quality and quarantine [3]. In Pakistan, a private-sector company initiated commercial food irradiation in 2010, and a total of 940 tons of legumes, spices, and fruits were processed in that year [4]. According to the Food Irradiation Treatment Facilities Database of the Joint FAO/IAEA Programme, around 50 tons of spices are irradiated per month in that Pakistani facility [5].

Ionizing radiation is effective against fungi common to hot peppers as well as total aerobic microorganisms. Previous work in our laboratory showed that total mold and Aspergillus counts in gamma-irradiated peppers achieved from $90 \%$ to $99 \%$ reduction at 2- and 4-kGy doses, respectively, while a radiation dose of $6 \mathrm{kGy}$ eliminated the fungal population [6]. Song et al. [7] indicated that gamma irradiation at $5 \mathrm{kGy}$ has potential for inactivating food borne pathogens (Escherichia coli O157:H7 and Salmonella typhimurium) in dried red pepper with minimal color changes. Similarly, Jung et al. [2] reported that a dose of $6 \mathrm{kGy}$ reduced the population of total aerobic microorganisms effectively without affecting major quality indicators of red pepper powder, such as pungency and red color.

Postharvest gamma radiation up to $1 \mathrm{kGy}$ did not significantly affect the quality of potatoes under non-refrigerated storage conditions [8]. Other studies carried out with pepper powder showed that radiation treatments have little impact on nutrients and overall quality under ideal storage temperatures $[9,10]$. However, the effect of irradiation treatments on the contents of bioactive compounds has not been thoroughly studied. Topuz and Ozdemir [11] recorded a significant decrease in carotenoids in sun-dried and dehydrated paprika subjected to irradiation. On the other hand, the concentration of capsaicinoids increased by $10 \%$ in irradiated paprika at $5 \mathrm{kGy}$ [12]. What is largely unknown is the effect of subsequent storage and retail display under ambient conditions on functional compounds of irradiated whole dried peppers. Thus, the present study was designed to explore the impact of multilevel gamma-radiation doses (2, 4 and $6 \mathrm{kGy})$ and subsequent storage on capsaicinoids and antioxidant compounds in hot peppers.

\section{Materials and Methods}

\subsection{Pepper Samples}

Hot peppers (Capsicum annuum L.) were grown in plastic tunnels under drip irrigation system at the Vegetable Research Area of the Institute of Horticultural Sciences (University of Agriculture, Faisalabad, Pakistan) and harvested at the red ripe stage with pedicels. The fruits were dried in the sun for 6 to 8 days with an average daily temperature of $39{ }^{\circ} \mathrm{C}$ and relative humidity of $36 \%$ before the storage experiments. The moisture content of dried samples was determined with the air-forced oven drying method (indirect distillation at $105^{\circ} \mathrm{C}$ ), according to Method $44-15 \mathrm{~A}$ of the American Association for Cereal Chemistry [13]. Moisture content in all hot pepper samples was $12 \%-13 \%$ after the sun-drying period.

\subsection{Irradiation Treatments and Storage Conditions}

Dried pods of hot pepper hybrids (200 g) were packed in synthetic low-density polyethylene bags $(9 \mu \mathrm{m}$ thick, 20 by $32 \mathrm{~cm}$ ) and irradiated at dose levels of 0 (control nonirradiated samples), 2, 4, and 6 kGy in a Co60 gamma irradiator (Model Issledovatel, Mytishhi, Russia) using a dose rate of $0.4461 \mathrm{kGy} / \mathrm{h}$ at the Nuclear Institute for Food and Agriculture (NIFA), Peshawar, Pakistan. Upon irradiation, the samples were transported to the laboratory under refrigeration $\left(4^{\circ} \mathrm{C}\right)$, analyzed immediately (day 0), and stored at $25{ }^{\circ} \mathrm{C}$ for three months (day 90). Experiments were carried out in triplicate, and three subsamples of 25 grams were taken from each package and used for chemical analysis. 


\subsection{Determination of Capsaicin and Dihydrocapsaicin}

A portion of $5 \mathrm{~g}$ from each subsample of hot pepper was oven-dried at $60{ }^{\circ} \mathrm{C}$ for $2-5$ days, cooled and then ground to dried pepper powder. Samples were analyzed by using a chromatographic method previously described [14]. A mixture of 1-g sample with $10 \mathrm{~mL}$ acetonitrile was placed in 120-mL glass bottles with Teflon-lined lids, capped and placed in a water bath at $80^{\circ} \mathrm{C}$ for $4 \mathrm{~h}$ and swirled manually every hour. The bottles were removed from the water bath and cooled at room temperature. The supernatant content of samples $\left(2-3 \mathrm{~mL}\right.$ ) was filtered through a $0.45 \mu \mathrm{m}$ filter (Millex ${ }^{\circledR}$-HV filter) using a 5-mL disposable syringe (Millipore, Bedford, MA, USA) into an HPLC sample vial. For the liquid chromatographic analysis of capsaicinoids, an HPLC system LC-10 (Shimadzu, Kyoto, Japan) equipped with an SPD-10A. UV-Vis detector (set at $280 \mathrm{~nm}$ wavelength) was used. The analysis was carried out with the isocratic mobile phase (acetonitrile:water, 60:40) at a flow rate of $1 \mathrm{~mL} / \mathrm{min}$ using a column Discovery C18 $(250 \times 4.6 \mathrm{~mm}, 5 \mu \mathrm{m})$ supplied by Supelco (Bellefonte, PA, USA). The limit of detection (LOD) was $0.1 \mu \mathrm{g} / \mathrm{g}$ for both capsaicinoids.

\subsection{Total Carotenoids}

Based on the Association of Official Analytical Chemists official Method 970.64 [15], two grams of hot pepper sample were ground using a mortar and pestle and transferred to a 100-mL flask covered with a stopper. The sample was blended for one minute with a mixture of $30 \mathrm{~mL}$ hexane:acetone:ethanol:toluene (10:7:6:7). For hot saponification, $2 \mathrm{~mL}$ of $40 \%$ methanolic $\mathrm{KOH}$ were pipetted into the flask, swirled for one minute and placed in a $56{ }^{\circ} \mathrm{C}$ water bath for $20 \mathrm{~min}$. The sample was cooled for one hour in the dark, and then, $30 \mathrm{~mL}$ of hexane were pipetted into the flask, dried over anhydrous sodium sulfate made up to volume and shaken vigorously for one minute. Upper phase was $50 \mathrm{~mL}$. Absorbance was measured at $436 \mathrm{~nm}$ using the IRMECO UV-Vis spectrophotometer Model U2020 with $\beta$-carotene (Sigma-Aldrich, St. Louis, MO, USA) as the standard.

\subsection{Ascorbic Acid}

Ascorbic acid was quantitatively determined according to the 2,6-dichlorophenolindophenol AOAC official Method 967.21 [15]. A sample of hot peppers ( $10 \mathrm{~g}$ ) was blended with $2.5 \mathrm{~mL}$ of $20 \%$ metaphosphoric acid, and distilled water was then added up to the 100-mL mark. Ten milliliters of the suspension were titrated with freshly-prepared standard of 2,6-dichlorophenolindophenol dye until a light, but distinct rose pink color persisted for $15 \mathrm{~s}$.

\subsection{Total Phenolic Compounds}

Total phenolic contents of hot peppers were analyzed using the modified Folin-Ciocalteu reagent method as described elsewhere [14]. About $0.5 \mathrm{~g}$ of the sample was macerated in $3 \mathrm{~mL} \mathrm{80 \%} \mathrm{aqueous}$ acetone with a mortar and pestle. The extracts were placed into tightly-sealed micro-tubes and maintained in darkness at $4{ }^{\circ} \mathrm{C}$ overnight. Samples were centrifuged at $1000 \mathrm{rpm}$ for $2 \mathrm{~min}$. A mixture of $135 \mu \mathrm{L} \mathrm{H}_{2} \mathrm{O}, 750 \mu \mathrm{L}$ 1/10 dilution Folin-Ciocalteu reagent (Sigma-Aldrich, St. Louis, MO, USA) and $600 \mu \mathrm{L} 7.5 \%(\mathrm{w} / \mathrm{v}) \mathrm{Na}_{2} \mathrm{CO}_{3}$ was added to $50 \mu \mathrm{L}$ of extract in $1.5 \mathrm{~mL}$ micro-tubes. After vortexing for $10 \mathrm{~s}$, the mixture was incubated at $45{ }^{\circ} \mathrm{C}$ in a water bath for $15 \mathrm{~min}$. Samples were allowed to cool to room temperature before reading the absorbance at $765 \mathrm{~nm}$ using the IRMECO UV-Vis spectrophotometer Model U2020. A blank was prepared from $50 \mu \mathrm{L} 80 \%$ aqueous acetone. The gallic acid standard curve was prepared from freshly-made $1 \mathrm{mg} / \mathrm{mL}$ gallic acid (Acros Organics, Geel, Belgium) in $80 \%$ aqueous acetone.

\subsection{Statistical Analysis}

Analysis of variance was computed with the data from each attribute using the STATISTICA Computer Program (Version 2003, StatSoft Inc., Tulsa, OK, USA). Experiments were performed according to a completely randomized design with factorial arrangement with three replicates for each 
treatment. The factor radiation dose had four levels $(0,2,4$ and $6 \mathrm{kGy})$ and the factor storage had two levels ( 0 and 90 days). There were eight treatment combinations and each treatment replicated thrice. The least significant difference test at the $5 \%$ level of probability was used to check the differences among mean values according to Hill and Lewicky [16].

\section{Results and Discussion}

The analysis of variance for the functional components of hot peppers is shown in Table 1. The analysis was conducted to determine whether there was significant difference between capsaicinoids and antioxidants with radiation treatments and storage time. Results indicated that radiation treatments had no significant effect on the concentrations of all chemical parameters under study. Storage duration, however, affected the levels of carotenoids and ascorbic acid significantly $(p<0.05)$; storage for 90 days resulted in significantly lower concentrations as compared to the day 0 .

Table 1. Anova table for a 2-factor analysis of variance on chemical data showing $p$ values.

\begin{tabular}{ccccccc}
\hline Source & DF & Capsaicin & Dihydrocapsaicin & Carotenoids & Ascorbic Acid & Phenolics \\
\hline Radiation (A) & 3 & 0.7274 & 0.7588 & 0.7260 & 0.0885 & 0.9828 \\
Storage (B) & 1 & 0.5322 & 0.4103 & $0.0489^{*}$ & $0.0001^{*}$ & 0.6193 \\
AB & 3 & 0.9751 & 0.9766 & 0.9582 & 0.7011 & 0.9908 \\
\hline
\end{tabular}

* indicates a statistically significant effect.

\subsection{Capsaicin and Dihydrocapsaicin Contents}

Hot pepper cultivars are rich in capsaicinoids, responsible for the specific taste of pepper fruits, which may also be used in pain relievers, due to their pharmacological properties [17]. On day 0 the concentration of capsaicin in control group (non-irradiated) was $23.2 \pm 5.0 \mathrm{mg} / 100 \mathrm{~g}$, and barely changed in $2 \mathrm{kGy}(23.9 \pm 5.5), 4 \mathrm{kGy}(23.0 \pm 5.6)$, and $6 \mathrm{kGy}(24.3 \pm 5.7)$ radiation dose treatment. Likewise, the levels of dihydrocapsaicin remained fairly stable from $13.7 \pm 3.2 \mathrm{mg} / 100 \mathrm{~g}$ in control group to $14.1 \pm 3.1$ ( $2 \mathrm{kGy}), 14.3 \pm 3.1$ (4 kGy), and $14.3 \pm 2.7$ (6 kGy) in irradiated samples. The effect of the subsequent storage during 90 days is presented in Figure 1. The levels of capsaicin and dihydrocapsaicin were essentially maintained during storage showing only minor losses of $3.4 \%$ and $4.2 \%$ on average, respectively. For both capsaicin and dihydrocapsaicin the lower losses during storage were observed in irradiated samples at $6 \mathrm{kGy}$.

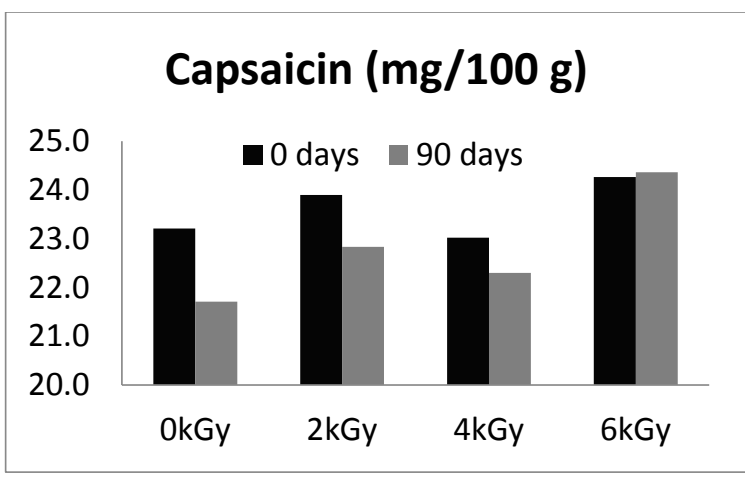

(a)

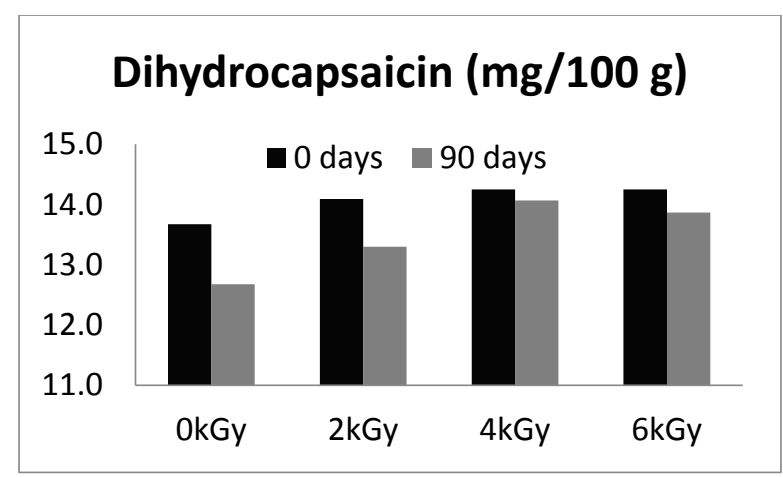

(b)

Figure 1. Effect of gamma radiation on (a) capsaicin and (b) dihydrocapsaicin concentrations in hot peppers during three months' storage.

The maximum concentration of capsaicin at day 0 was detected in the samples irradiated at $6 \mathrm{kGy}$ $(24.3 \mathrm{mg} / 100 \mathrm{~g})$, and so it was at the end of the storage period at day $90(24.4 \mathrm{mg} / 100 \mathrm{~g})$. Our finding is correlated with Subbulakshmi et al. [18] that the pungency of irradiated paprika tended to be greater 
when compared with non-radiated control. Similarly, Topuz and Ozdemir [12] found that an increase in capsaicinoids with the effect of irradiation could be explained by changing the conformation of the molecules in the food matrix which affects the extraction yield. Doses up to $5 \mathrm{kGy}$ of gamma irradiation led to capsaicinoids increases in paprika up to $10 \%$ in a dose-dependent manner.

\subsection{Total Carotenoids}

Capsicum fruits have been used as natural food colorants, and an increasing interest is being paid to the spice red pepper because of its economic importance and diversified composition [19]. An immediate decrease of carotenoids was observed for all the radiation treatments as compared to the control, and further reductions were observed over time during 3 months of storage. The initial concentration of carotenoids in control group at day 0 was $76.9 \pm 14.6 \mathrm{mg} / 100 \mathrm{~g}$ and levels gradually declined by $8 \%$ following treatment at radiation doses of $2 \mathrm{kGy}(74.9 \pm 13.9), 4 \mathrm{kGy}(72.1 \pm 13.1)$, and $6 \mathrm{kGy}(70.7 \pm 12.5)$. These results indicated that carotenoids are somewhat sensitive to gamma radiation as their concentrations decreased with increasing irradiation doses. This decreasing trend may be attributed to absorbed energy assisted by irradiation doses up to $6 \mathrm{kGy}$ and/or increase in the rate of the oxidation reaction. It is well established that as ionizing radiation passes through food, it creates a trail of chemical transformations by primary and secondary radiolysis effects [20]. As shown in Figure 2, the evolution of carotenoids during storage showed significant losses of $12.0 \%$ in control peppers $(p<0.05)$.

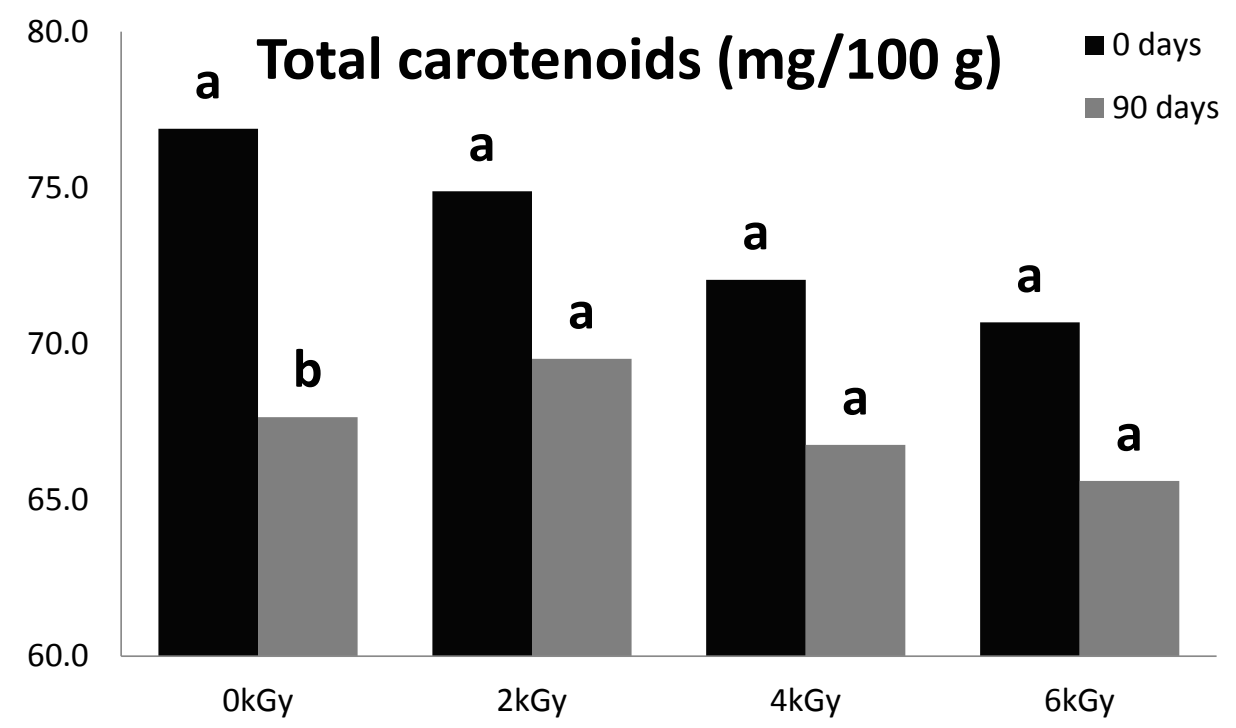

Figure 2. Effect of gamma radiation on total carotenoids concentration in hot peppers during three months' storage; $\mathbf{a}, \mathbf{b}$ indicate differences between these pairs of treatment means at $p<0.05$.

Topuz and Ozdemir [11] observed in paprika that carotenoid reduction due to irradiation was possibly caused by an increase in oxidation reaction under gamma radiation and also secondary oxidative effects of free radical $\left(\mathrm{H}_{2} \mathrm{O}_{2}, \mathrm{O}_{3}\right.$ and $\left.\mathrm{OH}\right)$ formation during radiation. Significant losses of carotenoids (about $40 \%-60 \%$ ) have been reported for cinnamon, oregano, parsley, rosemary, bird pepper, and sage after gamma irradiation at a dose of $10 \mathrm{kGy}$ [21].

\subsection{Ascorbic Acid}

Peppers are an excellent source of ascorbic acid that besides the nutritional relevance, might contribute to prevent oxidative damage in the commodity [22]. The tested ionizing radiation doses immediately after treatments at 2-, 4- and 6 kGy did not significantly affect ascorbic acid concentrations as compared to the control. Thus, non-irradiated samples contained $28.5 \pm 2.6 \mathrm{mg} / 100 \mathrm{~g}$, and levels 
following irradiation were $28.4 \pm 1.7$ ( $2 \mathrm{kGy}), 27.8 \pm 1.7$ (4 kGy), and $27.7 \pm 2.0$ (6 kGy). However, ascorbic acid decreased significantly $(p<0.05)$ in both control and gamma-irradiated peppers during storage for 90 days (Figure 3). The general tendency for the amount of ascorbic acid that was lost was similar for all the irradiation treatments and it was highest (14.0\%) at $6 \mathrm{kGy}$. Since ascorbic acid is highly prone to oxidation upon wounding [23], the modest reduction in treated samples is an indication that gamma radiation at tested doses does not cause significant injuries in pepper fruits.

\section{Ascorbic acid $(\mathrm{mg} / \mathbf{1 0 0} \mathrm{g}) \quad-0$ days}

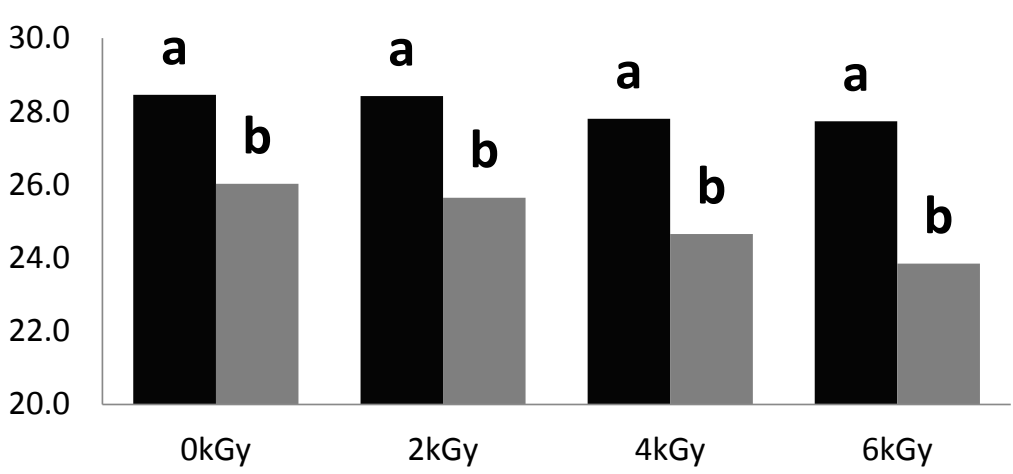

Figure 3. Effect of gamma radiation on ascorbic acid concentration in hot peppers during three months' storage; $\mathbf{a}, \mathbf{b}$ indicate differences between these pairs of treatment means at $p<0.05$.

So far, research information regarding the effect of irradiation doses on ascorbic acid in dry hot peppers during storage is scarce. However, Bib et al. [24] reported that ascorbic acid concentration decreased by $7 \%$ in dried garlic powder irradiated at $1 \mathrm{kGy}$ during five months' storage. Similarly, Calucci et al. [21] found that ascorbic acid concentration decreased in different aromatic herbs and spices an average of $21 \%$ when these were irradiated at a dose of $10 \mathrm{kGy}$ and stored for three months. Changes reported for total ascorbate in orange juice that was gamma irradiated up to $8.7 \mathrm{kGy}$ revealed an approximate linear loss of $2.7 \%$ for each kGy increase [25].

\subsection{Total Phenolic Compounds}

Peppers contain phenolic compounds (mainly flavonoids), which play important roles in human health as antioxidants, and they possess anti-inflammatory, anti-allergic, anti-viral, and anti-bacterial activities [1]. The ionizing radiation treatments did not cause marked modifications in total phenolic compounds at day 0 . The concentration in control non-irradiated group was $43.9 \pm 12.5 \mathrm{mg} / 100 \mathrm{~g}$, and attained $44.2 \pm 11.9 \mathrm{mg} / 100 \mathrm{~g}$ after a radiation dose of $6 \mathrm{kGy}$. As shown in Figure 4, the concentration of total phenolic compounds during storage showed somewhat greater stability in irradiated samples (fell only by 1 to $4 \%$ ) than in the control group (loss of $6.5 \%$ ). Therefore, these results indicated that irradiation up to $6 \mathrm{kGy}$ is effective for the preservation of total phenolic contents in hot peppers even though there was oxygen inside the package.

Limited information is available in the literature on the effect of gamma radiation on total phenolic contents of dry hot peppers and other spices. The results of present study are in line with the findings of Abrar et al. [26] that no significant changes in total phenolic compounds were observed in red chilies irradiated up to $6 \mathrm{kGy}$ during three months' storage. In contrast, Variyar et al. [27] found increased phenolic acid concentrations in cloves and nutmeg after irradiation. They further revealed that increase in phenolic contents was associated with the degradation of tannins in these spices. Similarly, Harrison and Were [28] also reported increase in total phenolic contents in almond skin after irradiation at $4 \mathrm{kGy}$.

Limited information is available in the literature on the effect of gamma radiation on total phenolic contents of dry hot peppers and other spices. The results of present study are in line with the findings of Abrar et al. [26] that no significant changes in total phenolic compounds were observed in red chilies 
irradiated up to $6 \mathrm{kGy}$ during three months' storage. In contrast, Variyar et al. [27] found increased phenolic acid concentrations in cloves and nutmeg after irradiation. They further revealed that increase in phenolic contents was associated with the degradation of tannins in these spices. Similarly, Harrison and Were [28] also reported increase in total phenolic contents in almond skin after irradiation at $4 \mathrm{kGy}$.

\section{Total phenolics (mg/100 g)}

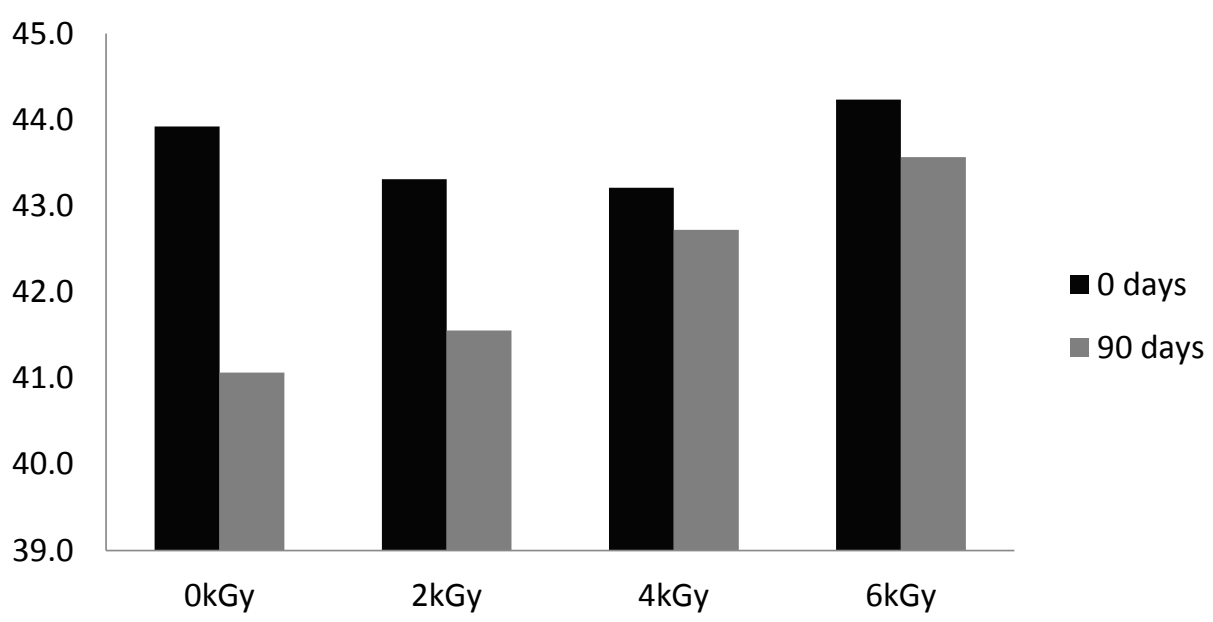

Figure 4. Effect of gamma radiation on total phenolic contents in hot peppers during three months' storage.

\section{Conclusions}

Overall, neither decontamination treatment by gamma irradiation nor subsequent ambient storage could appreciably influence the contents of functional components in hot peppers, except for some losses of carotenoids and ascorbic acid that did not reach the 15 percent. These results revealed that gamma irradiation up to $6 \mathrm{kGy}$ can maintain the quality of hot peppers to meet the export markets requirements.

Acknowledgments: This work was supported by the Higher Education Commission, Islamabad, Pakistan. The authors are grateful for being provided laboratory facilities at the Nuclear Institute for Agriculture and Biology, Faisalabad, Pakistan. The corresponding author is also highly grateful for the support of the University of Agriculture, Faisalabad, Pakistan. DGA/ESF (project number Grupo A01) provided funds for covering the costs to publish in open access.

Author Contributions: The present study was performed by Q.I. under direct supervision of M.A. and M.R.A., both of whom conceived and designed the experiments. A.N., S.M.K. and T.A. provided advice on analytical methods. A.A. contributed to the statistical analysis and data interpretation. All authors read and approved the final manuscript.

Conflicts of Interest: The authors declare no conflict of interest. The founding sponsors had no role in the design of the study; in the collection, analyses, or interpretation of data; in the writing of the manuscript, and in the decision to publish the results.

\section{References}

1. Bae, H.; Jayaprakasha, G.K.; Jifon, J.; Patil, B.S. Variation of antioxidant activity and the levels of bioactive compounds in lipophilic and hydrophilic extracts from hot pepper (Capsicum spp.) cultivars. Food Chem. 2012, 134, 1912-1918. [CrossRef] [PubMed]

2. Jung, K.; Song, B.S.; Kim, M.J.; Moon, B.G.; Go, S.M.; Kim, J.K.; Lee, Y.J.; Park, J.H. Effect of X-ray, gamma ray, and electron beam irradiation on the hygienic and physicochemical qualities of red pepper powder. LWT-Food Sci. Technol. 2015, 63, 846-851. [CrossRef]

3. Sadecka, J. Irradiation of spices-A review. Czech J. Food Sci. 2007, 25, 231-242.

4. Kume, T.; Todoriki, S. Food irradiation in Asia, the European Union and the United States: A Status update. Radioisotopes 2013, 62, 291-299. [CrossRef] 
5. FITF (Food Irradiation Treatment Facilities). FITF Database Food and Environmental Subprogramme of the Joint FAO/IAEA Division of Nuclear Techniques in Food and Agriculture. Available online: https: //nucleus.iaea.org/fitf/Default.aspx (accessed on 4 June 2016).

6. Iqbal, Q.; Amjad, M.; Asi, M.R.; Ariño, A. Mold and aflatoxin reduction by gamma radiation of packed hot peppers and their evolution during storage. J. Food Protect. 2012, 75, 1528-1531. [CrossRef] [PubMed]

7. Song, W.J.; Sung, H.J.; Kim, S.Y.; Kim, K.P.; Ryu, S.; Kang, D.H. Inactivation of Escherichia coli O157:H7 and Salmonella typhimurium in black pepper and red pepper by gamma irradiation. Int. J. Food Microbiol. 2014, 172, 125-129. [CrossRef] [PubMed]

8. Mahto, R.; Das, M. Effect of gamma irradiation on the physico-mechanical and chemical properties of potato (Solanum tuberosum L.), cv. 'Kufri Sindhuri', in non-refrigerated storage conditions. Postharvest Biol. Technol. 2014, 92, 37-45. [CrossRef]

9. Lee, J.H.; Sung, T.H.; Lee, K.T.; Kim, M.R. Effect of gamma-irradiation on color, pungency, and volatiles of Korean red pepper powder. J. Food Sci. 2004, 69, 585-592. [CrossRef]

10. Rico, C.W.; Kim, G.R.; Ahn, J.J.; Kim, H.K.; Furuta, M.; Kwon, J.H. The comparative effect of steaming and irradiation on the physicochemical and microbiological properties of dried red pepper (Capsicum annuum L.). Food Chem. 2010, 119, 1012-1016. [CrossRef]

11. Topuz, A.; Ozdemir, F. Influence of gamma radiation and storage on the carotenoids of sun-dried and dehydrated paprika. J. Agric. Food Chem. 2003, 51, 4972-4977. [CrossRef] [PubMed]

12. Topuz, A.; Ozdemir, F. Influence of gamma radiation and storage on the capsaicinoids of sun-dried and dehydrated paprika. Food Chem. 2004, 86, 509-515. [CrossRef]

13. AACC (American Association of Cereal Chemists). Association of Cereal Chemists Approved Methods of AACC, 5th ed.; AACC: St. Paul, MN, USA, 2000.

14. Iqbal, Q.; Amjad, M.; Asi, M.R.; Ariño, A. Characterization of capsaicinoids and antioxidants in hot peppers as influenced by hybrid and harvesting stage. Plant Foods Hum. Nutr. 2013, 68, 358-363. [CrossRef] [PubMed]

15. AOAC (Association of Official Analytical Chemists). Official Methods of Analysis of AOAC International, 19th ed.; AOAC International: Gaithersburg, MD, USA, 2012.

16. Hill, T.; Lewicki, P. Statistics: Methods and Applications; StatSoft: Tulsa, OK, USA, 2007.

17. Liu, Y.; Nair, M.G. Non-pungent functional food components in the water extracts of hot peppers. Food Chem. 2010, 122, 731-736. [CrossRef]

18. Subbulakshmi, G.; Udipi, S.; Raheja, R.; Sharma, A.; Padwal Desai, S.R.; Nair, P.M. Evaluation of sensory attributes and some quality indices of irradiated spices. J. Food Sci. Technol. 1991, 28, 396-397.

19. Iqbal, Q.; Amjad, M.; Asi, M.R.; Ariño, A.; Ziaf, K.; Nawaz, A.; Ahmad, T. Stability of Capsaicinoids and Antioxidants in Dry Hot Peppers under Different Packaging and Storage Temperatures. Foods 2015, 4, 51-64. [CrossRef]

20. EFSA (European Food Safety Authority). Scientific opinion on the chemical safety of irradiation of food. EFSA J. 2011, 9, 1930.

21. Calucci, L.; Pinzino, C.; Zandomeneghi, M.; Capocchi, A.; Ghiringhelli, S.; Saviozzi, F.; Tozzi, S.; Galleschi, L. Effect of gamma radiation on the free radical and antioxidant contents in nine aromatic herbs and spices. J. Agric. Food Chem. 2003, 51, 927-934. [CrossRef] [PubMed]

22. Rietjens, I.M.; Boersma, M.G.; de Haan, L.; Spenkelink, B.; Awad, H.M.; Cnubben, N.H.; Zanden, J.J.; Woude, H.; Alink, G.M.; Koeman, J.H. The pro-oxidant chemistry of the natural antioxidants vitamin C, vitamin E, carotenoids and flavonoids. Environ. Toxicol. Pharmacol. 2002, 11, 321-333. [CrossRef]

23. Cuvi, M.J.A.; Vicente, A.R.; Concellón, A.; Chaves, A.R. Changes in red pepper antioxidants as affected by UV-C treatments and storage at chilling temperatures. LWT-Food Sci. Technol. 2011, 44, 1666-1671. [CrossRef]

24. Bib, N.; Khattak, A.; Zeb, A.; Mehmood, Z. Irradiation and packaging-food safety aspects and shelf life extension of solar dried garlic (Allium sativum) powder. Am. J. Food Technol. 2007, 3, 118-126. [CrossRef]

25. Fan, X.; Thayer, D.W.; Handel, A.P. Nutritional quality of irradiated orange juice. J. Food Process. Preserv. 2002, 26, 195-211. [CrossRef]

26. Abrar, M.; Anjum, F.M.; Zahoor, T.; Nawaz, H. Effect of storage period and irradiation doses on red chillies. Pak. J. Nutr. 2009, 8, 1287-1291. [CrossRef] 
27. Variyar, P.S.; Bandypadhyay, C.; Thomas, P. Effect of gamma radiation on the phenolic acid of some Indian spices. Int. J. Food Sci. Technol. 1998, 33, 533-537. [CrossRef]

28. Harrison, K.; Were, L.M. Effect of gamma radiation on total phenolic content yield and antioxidant capacity of almond skin extracts. Food Chem. 2007, 102, 932-937. [CrossRef] 